\title{
Comparison of Carotid Endarterectomy and Stenting for Symptomatic Internal Carotid Artery Near-Occlusion
}

\author{
(D). Kim, DS. Male, (DD. Damania, (DB.S. Jahromi, and DR.P. Tummala
}

\begin{abstract}
BACKGROUND AND PURPOSE: Carotid near-occlusion is defined as severe stenosis of the internal carotid artery with partial or full collapse of the distal vessel wall. The major studies evaluating carotid revascularization excluded patients with carotid near-occlusion. Given the paucity of data in the literature, we attempted to evaluate the safety of carotid endarterectomy and carotid artery stenting in carotid near-occlusion.
\end{abstract}

MATERIALS AND METHODS: A retrospective data base review was performed from January 2010 to December 2018 to identify patients who underwent carotid endarterectomy or carotid artery stenting for symptomatic ICA near-occlusion and had 1-month clinical and imaging follow-up with carotid sonography. The medical records and imaging studies of patients with ICA near-occlusion were selected for analysis.

RESULTS: Forty-five patients met the criteria for ICA near-occlusion, of whom 39 were included in the study, given insufficient 1-month follow-up on 6 patients. Of the 39 patients, 25 underwent carotid endarterectomy and 14 underwent carotid artery stenting. All patients had technically successful immediate revascularization of the ICA. Most (33 of 39) had 1-year follow-up postoperatively. Patients with carotid artery stenting had $20 \%$ restenosis and $79 \%$ vessel maturation rates, while patients with carotid endarterectomy had $17.4 \%$ restenosis and $84 \%$ vessel maturation. There was no significant difference in periprocedural complication rates between the 2 procedures.

CONCLUSIONS: Carotid artery stenting shows similar outcomes in restenosis and vessel maturation rates compared with carotid endarterectomy for ICA near-occlusion. There were no major differences between the 2 treatments in clinical outcomes or periprocedural complications. Carotid artery stenting is a revascularization option for carotid near-occlusion if the patient is considered at high risk for carotid endarterectomy.

ABBREVIATIONS: CAS = carotid artery stenting; $C C A=$ common carotid artery; CEA = carotid endarterectomy; ECST = European carotid surgery trial; PSV = peak systolic velocity

$\mathbf{R}^{\mathrm{e}}$ vascularization of symptomatic near-occlusion (also termed "pseudoocclusion") of the extracranial internal carotid artery is a controversial subject, partly due to an unclear natural history of the condition. Carotid artery near-occlusion was first described in 1970 as severe narrowing of the ICA with distal arterial narrowing secondary to hypoperfusion. ${ }^{1}$ The NASCET ${ }^{2}$ and the European Carotid Surgery Trial (ECST) ${ }^{3}$ collaborators defined nearocclusion as the presence of at least 2 of following 4 criteria: 1)

Received February 24, 2019; accepted after revision April 22.

From the Departments of Neurology, Neurosurgery, and Radiology (J.K., S.M., R.P.T.), University of Minnesota, Minneapolis, Minnesota; Department of Medicine (D.D.), State University of New York, Downstate Medical Center, Brooklyn, New York; and Department of Neurological Surgery (B.S.J.), Northwestern University, Chicago, Illinois

Please address correspondence to Jae Kim, MD, Department of Neurology, University of Minnesota, 420 Delaware St SE, Minneapolis, MN 55455; e-mail: kimx3990@umn.edu

http://dx.doi.org/10.3174/ajnr.A6085

delayed contrast filling of the ipsilateral ICA compared with the external carotid artery, 2) evidence of collateral supply to the ipsilateral intracranial vessels, 3 ) reduction in the ipsilateral distal cervical ICA diameter compared with the contralateral ICA, and 4) reduction in the ipsilateral distal ICA diameter compared with the external carotid artery diameter beyond the facial and occipital artery origin. ${ }^{4}$ Originally, near-occlusion was defined in association with full collapse of the distal ICA, otherwise known as a "string sign," but it was recently redefined, recognizing that nearocclusion without full collapse can progress eventually to full collapse with increasing risk of ipsilateral ischemic stroke. ${ }^{5}$ In this context, "collapse" refers to reduction of the vessel caliber secondary to poor filling. Currently, near-occlusion of the ICA is recognized as a spectrum of severe atherosclerotic stenosis with or without full collapse of the distal vessel: Full collapse of the ICA distal to the stenosis is threadlike, while partial collapse refers to a smaller caliber of the vessel than the original size but without the threadlike appearance. ${ }^{6}$ Due to concern for periocclusive embo- 
lism, near-occlusions were revascularized historically with emergency carotid endarterectomy (CEA). Currently, emergency revascularization of near-occlusion is not routinely performed; moreover, the utility of treating these lesions at all with revascularization rather than medical therapy is questionable.

The risk of ipsilateral stroke increases with the degree of carotid stenosis, but paradoxically, the risk of stroke with near-occlusion is lower than that of severe (defined as 70\%-99\%) carotid stenosis. Analysis from a NASCET substudy reported a modest benefit with CEA, while the ECST reported no statistically significant benefit of surgical treatment of near-occlusion. Patient-level pooled analysis of NASCET and ECST found only a minor benefit of CEA in symptomatic carotid near-occlusion. ${ }^{4}$

Historically, revascularization of near-occlusion was thought to carry a high risk, but NASCET and ECST found no increased treatment risk in these patient subgroups compared with the severe-stenosis subgroups. ${ }^{7}$ Similar findings with endovascular treatment have also been described. ${ }^{8,9}$ Despite the reports of revascularization in carotid near-occlusion with CEA and carotid artery stenting (CAS), there are limited data available on the comparison of surgical treatment with endovascular treatment. ${ }^{10}$ In NASCET and ECST, a large number of patients met the criteria for near-occlusion on post hoc analysis. In these trials, 137 of 662 (21\%) and 125 of 554 (23\%), respectively, met the criteria for near-occlusion. ${ }^{11}$ This finding meant that at least 1 in 5 patients with $\geq 70 \%$ symptomatic carotid stenosis actually had near-occlusion on further analysis. More recent trials of CEA versus CAS for symptomatic stenosis have excluded this subgroup. ${ }^{12,13}$ Therefore, it is important to identify the merits and disadvantages of CAS versus CEA for revascularization of carotid near-occlusion. In this study, we report our experience of both of these revascularization strategies for symptomatic carotid near-occlusion.

\section{MATERIALS AND METHODS \\ Patient Selection}

From January 2010 to December 2018, we reviewed all patients who underwent CEA and CAS for symptomatic carotid stenosis and had 1-month clinical and sonography follow-up at 2 tertiary care centers. The diagnosis of near-occlusion, which met the criteria established previously, was made by reviewing catheter angiography imaging. ${ }^{4}$ The patients underwent CEA or CAS per risk stratification based on medical comorbidities and imaging findings. Patients underwent CAS only when they had high risk factors for CEA. The electronic medical record was reviewed to obtain demographic information as well as clinical follow-up, imaging studies, and operative notes.

\section{Ethics}

The institutional review boards of each institution approved the study procedures. Both institutional review boards (University of Minnesota, Minneapolis, Minnesota, and University of Rochester, Rochester, New York) approved a waiver of informed consent.

\section{Technique for CEA}

All patients received preoperative aspirin and/or clopidogrel and underwent surgery under general anesthesia with neurophysio- logic monitoring, including somatosensory-evoked potentials and electroencephalography. Patients were anticoagulated with intravenous heparin before cross-clamping. After cross-clamping of the common carotid artery (CCA) and external and internal carotid arteries, an arteriotomy was performed to expose the plaque. The plaque was dissected off the intima until a smooth taper was achieved in the internal carotid artery. Back-bleeding from the internal carotid artery was confirmed in all patients before closure of the arteriotomy. Patch angioplasty was performed at the discretion of the surgeon on the basis of the caliber of the distal hypoplastic internal carotid artery.

\section{Technique for CAS}

All patients received daily aspirin and clopidogrel at least 5 days before the procedure, which was performed with the patient under conscious sedation and local anesthesia. A modified Seldinger technique was used for the transfemoral arterial access. All patients were loaded with 70-100 U per kilogram of body weight of intravenous heparin to maintain an activated clotting time between 250 and 350 seconds following placement of a $6 \mathrm{~F}$ vascularaccess sheath in the distal CCA. In most cases, a distal embolic protection device could not be advanced across the near-occlusion without predilation. A submaximal prestent angioplasty was performed using a Maverick balloon dilation catheter (Boston Scientific, Natick, Massachusetts) or a Gateway (Stryker, Kalamazoo, Michigan) noncompliant balloon over a 0.014-inch microwire. Next, a distal embolic protection system (Spider FX, Covidien, Plymouth, Minnesota; or FilterWire EZ, Boston Scientific) was navigated and deployed in the distal cervical ICA. A Precise self-expanding stent (Cordis, Fremont, California) was positioned over the stenotic segment, and the size of the stent was based on the distal CCA diameter. A poststent balloon angioplasty was performed if there was persistent stenosis of $>50 \%$ following stent placement. Control cerebral angiography was performed after retrieval of the distal embolic filter.

\section{Follow-Up and Assessment}

A full neurologic examination was performed at the end of each procedure. Patients were observed for 24 hours with hourly neurologic examinations along with continuous cardiac monitoring. Patients were typically discharged on postoperative day 1 or 2 . Patients having undergone CAS remained on aspirin and clopidogrel for at least 1 month and then aspirin thereafter. Patients having undergone CEA were continued on aspirin and/or clopidogrel. All patients had 1-month clinical and carotid sonography follow-up, while most patients (33/39) had 1-year clinical and imaging follow-up. Stroke was defined by any acute focal neurologic change as determined by a neurologist or neurosurgeon during the follow-up period. Carotid restenosis was defined as sonographic findings of an ICA peak systolic velocity (PSV) of $\geq 300$ $\mathrm{cm} / \mathrm{s}$ or an ICA/CCA PSV ratio of $\geq 3.8$, corresponding to $\geq 70 \%$, and vessel maturation was defined as 1-year carotid sonography follow-up with a PSV of $<200$ and an ICA/CCA PSV ratio of $<2 .{ }^{14}$ Myocardial infarction was defined as an elevation of cardiac enzymes or electrocardiographic changes along with demonstration of abnormalities of cardiac wall motion. 
Table 1: Demographics, vascular risk factors, and clinical/imaging findings

\begin{tabular}{lccc}
\hline & CAS $(\boldsymbol{n}=\mathbf{1 4})$ & CEA $(\boldsymbol{n}=\mathbf{2 5})$ & $\boldsymbol{P}$ Value \\
\hline Mean Age (y) & 66.2 & 65.4 & .80 \\
Sex (\%) & & & .16 \\
$\quad$ Male & $7(50 \%)$ & $19(76 \%)$ & \\
$\quad$ Female & $7(50 \%)$ & $6(24 \%)$ & \\
Comorbidities (\%) & & & \\
$\quad$ Hypertension & $11(79 \%)$ & $19(76 \%)$ & 1.00 \\
$\quad$ Smoking & $6(43 \%)$ & $14(56 \%)$ & .51 \\
$\quad$ Hyperlipidemia & $5(36 \%)$ & $11(44 \%)$ & .74 \\
$\quad$ Diabetes mellitus & $2(14 \%)$ & $7(28 \%)$ & .44 \\
$\quad$ Coronary artery disease & $2(14 \%)$ & $8(32 \%)$ & .28 \\
Clinical presentation (\%) & & & .03 \\
$\quad$ TIA & $8(57 \%)$ & $5(20 \%)$ & \\
$\quad$ Ischemic stroke & $6(43 \%)$ & $20(80 \%)$ & \\
Imaging finding (\%) & & & \\
$\quad$ Full collapse & $6(43 \%)$ & $14(56 \%)$ & .51 \\
\hline
\end{tabular}

\section{Statistical Analysis}

Comparisons between the 2 groups were performed with descriptive statistics and univariate comparison tests. For categoric variables, the Fisher exact test was used. For continuous variables, a 2 -tailed Student $t$ test was used. A $P$ value $<.05$ was the threshold of statistical significance. All statistical analyses were performed with SPSS 24 (IBM, Armonk, New York).

\section{RESULTS}

From January 2010 through December 2018, a total of 45 patients who underwent either CEA or CAS for symptomatic near-occlusion were identified. Of these, only 39 patients who had 1-month clinical and sonographic follow-up were included in the study analysis. The distribution of baseline patient characteristics, comorbidities, and interventions is shown for the CEA and CAS groups in Table 1. The mean ages in the CEA and CAS groups were 65.4 (10) years and 66.2 (9) years, respectively. Seventy-six percent of patients in the CEA group were men compared with $50 \%$ in the CAS group. All patients had symptomatic ICA near-occlusion that was treated successfully with either CEA or CAS. Fourteen (56\%) patients in the CEA group had full collapse, while 6 (43\%) patients in the CAS group had full collapse. A significantly higher number of patients presented with ischemic stroke over TIA in the CEA group (80\%) compared with the CAS group (43\%). There were no significant differences between the 2 groups in demographics, comorbidities, and baseline imaging.

There was 1 periprocedural complication in the CEA group, which was due to reperfusion injury with resulting subarachnoid hemorrhage without neurologic consequences. There was 1 death in the CAS group due to acute heart failure 14 months after stent placement. One-year imaging data were available in 33 of 39 patients. At 1 year, restenosis of $\geq 70 \%$ was identified in 4 of 23 $(17.4 \%)$ patients in the CEA group and 2 of $10(20 \%)$ patients in the CAS group using sonographic criteria. All patients who developed restenosis were asymptomatic. Vessel maturation with improvement in the distal vessel caliber occurred in most of the revascularized patients in the CEA and CAS groups, $84 \%$ and $79 \%$, respectively (Table 2). There were no significant differences in clinical or imaging outcomes between the 2 groups.

Six patients ( 3 with CEA, 3 with CAS) were treated for symptomatic near-occlusion but were excluded from this study due to insufficient clinical and imaging follow-up. Of these 6 patients, no
Table 2: Outcomes for CEA and CAS groups

\begin{tabular}{|c|c|c|c|}
\hline Outcome (\%) & CAS $(n=14)$ & CEA $(n=25)$ & $\begin{array}{c}P \\
\text { Value }\end{array}$ \\
\hline Restenosis & $2 / 10(20 \%)$ & $4 / 23(17.4 \%)$ & 1.0 \\
\hline $\begin{array}{l}\text { Follow-up } \\
\text { intervention }\end{array}$ & $1(7 \%)$ & $3(12 \%)$ & 1.0 \\
\hline Vessel maturation & $11(79 \%)$ & $21(84 \%)$ & 0.7 \\
\hline $\begin{array}{l}\text { Perioperative } \\
\text { complication }\end{array}$ & $0(0 \%)^{\mathrm{a}} ; 1 / 17(5.9 \%)$ & $1(4 \%)^{\mathrm{a}} ; 1 / 28(3.6 \%)$ & $1.0^{\mathrm{a}} ; 1.0$ \\
\hline $\begin{array}{l}\text { Stroke/Ml/death } \\
\text { at } 1 \mathrm{yr}\end{array}$ & $1(7 \%)$ & $0(0 \%)$ & .36 \\
\hline
\end{tabular}

Note:-Ml indicates myocardial infarction.

a Perioperative complication rates after including an additional 6 patients (CAS $=3$, $\mathrm{CEA}=3$ ) who were otherwise excluded from analyses due to insufficient follow-up.

patients in the CEA group developed complications, while 1 patient in the CAS group experienced a postoperative femoral pseudoaneurysm as well as reperfusion intracerebral hemorrhage. The perioperative complication rate between CEA and CAS groups, excluding these 6 patients, was $1 / 25(4 \%)$ versus $0 / 14(0 \%)$ $(p=1.0)$ compared with $1 / 28(3.6 \%)$ versus $1 / 17(5.9 \%)(p=1.0)$ upon including these patients (Table 2). The patient who had complications was noted to have a femoral pseudoaneurysm at the end of angiography, and it was obliterated with sonographyguided manual compression. Within an hour after the procedure, the same patient developed hemiparesis and aphasia with an NIHSS score of 6 secondary to reperfusion intracerebral hemorrhage in the basal ganglia and subinsular region measuring $44 \mathrm{~mL}$. The patient's examination findings remained stable, and the patient was discharged to an acute rehabilitation center on postoperative day 7. Subsequent follow-up data were insufficient.

\section{Illustrative Cases}

Patients with CEA. A 78-year-old man with coronary artery disease and hyperlipidemia was admitted with sudden onset of transient slurred speech and left facial droop. Initial MR angiography of the neck revealed an occluded right ICA, but subsequent conventional carotid angiography showed a right ICA near-occlusion with full collapse (Fig 1). On day 2 of the admission, the patient was brought to the operating room for CEA. Due to the very small caliber of the ICA, patch angioplasty was performed. The patient was extubated immediately after the procedure, and no neurologic changes were documented. He was discharged 3 days after the operation. On 1-month and 1-year follow-up, he was neurologically at baseline without deficit, with 1-year follow-up carotid sonography showing a right ICA PSV of $108 \mathrm{~cm} / \mathrm{s}$ and a right ICA/CCA PSV ratio of 1.62 .

Another patient, a 62-year-old woman with coronary artery disease, hypertension, diabetes mellitus, and hyperlipidemia, was admitted with intermittent left-arm numbness and weakness for 2 months. MR imaging revealed a subacute right parietal lobe infarct, and an initial MR angiogram of the neck revealed an occluded right ICA. Subsequent CT angiography of the neck and conventional carotid angiography showed a right ICA near-occlusion with full collapse. The patient underwent CEA with patch angioplasty and had no neurologic changes postoperatively. On 1- and 6-month follow-up, she was neurologically at baseline without deficit. At 6 months, she underwent a neck CTA that revealed no residual stenosis and complete resolution of vessel collapse compared with the baseline CTA (Fig 2). 


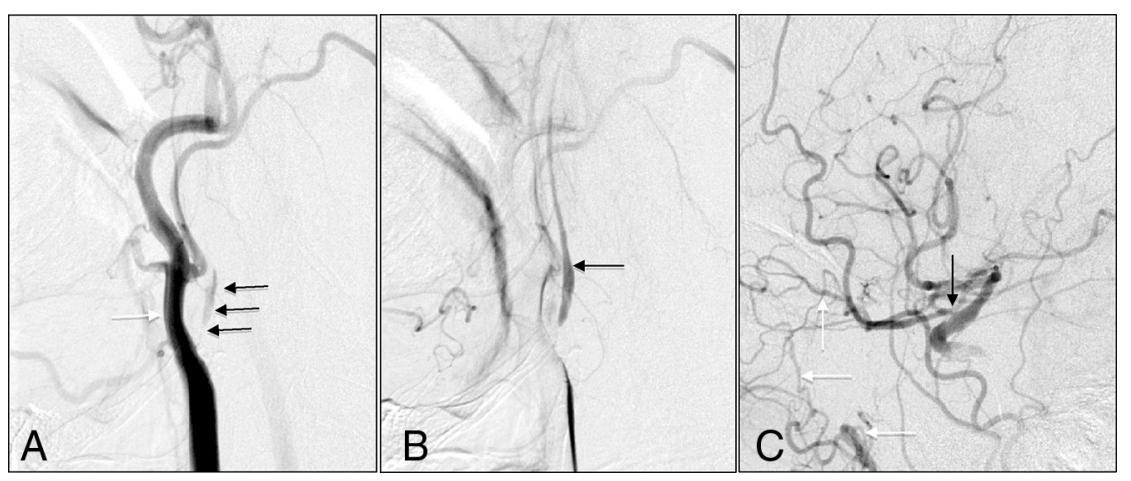

FIG 1. A, Early arterial phase shows severe ICA stenosis (black arrows) with a larger caliber external carotid artery (white arrow). B, Later arterial phase shows delayed filling of distal ICA (black arrow). C, Collateral filling of the distal ICA by the ophthalmic artery (black arrow) from the internal maxillary artery branch (white arrows).
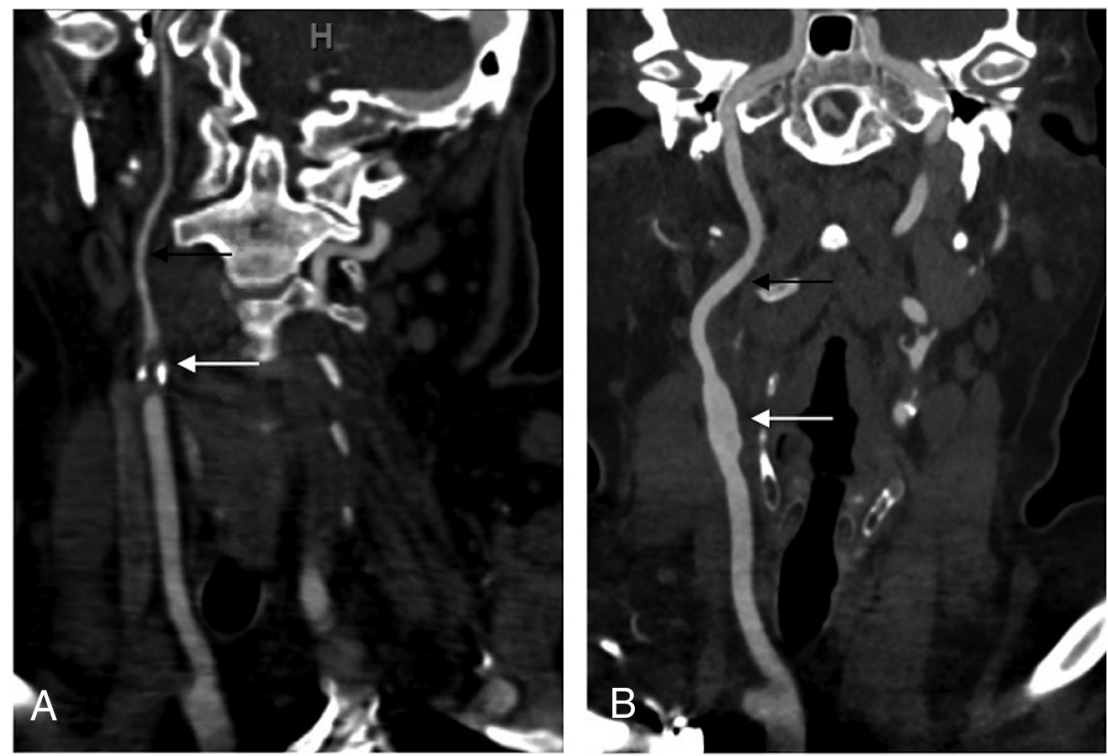

FIG 2. A, Baseline CTA of the neck revealing severe stenosis of the right ICA at the origin (white arrow) with collapse of the distal wall (black arrow). B, Follow-up CTA of the neck after treatment with CEA. There is no evidence of residual stenosis (white arrow) with maturation or regaining of the caliber of the distal ICA (black arrow).

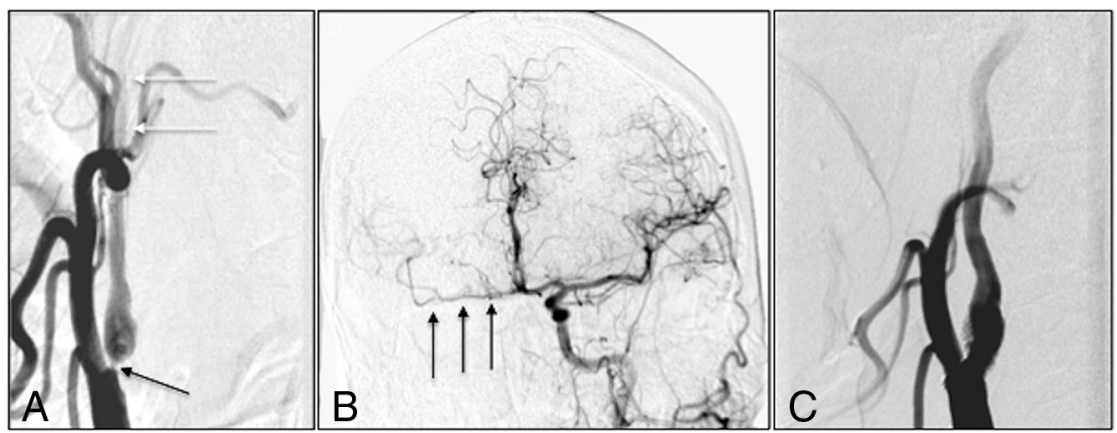

FIG 3. A, Early arterial phase shows severe right ICA stenosis (black arrow) with delayed distal ICA filling (white arrows). B, Cross-filling of the right middle cerebral artery (black arrows) after left carotid injection. C, Poststent right carotid injection shows brisk filling of distal ICA.

Patient with CAS. A 66-year-old man was admitted with left-arm and leg weakness for 2 weeks, with noncontrast CT of the head revealing a subacute right-frontal ischemic stroke. CT angiography showed severe stenosis of the right ICA, and the patient underwent conventional angiography, which revealed near-occlusion of the right ICA without full collapse and delayed filling distally (Fig $3 A$ ). Left carotid injection showed cross-filling of the right middle cerebral artery (Fig 3B). Because of the patient's immobile neck, we decided to pursue stent revascularization. After positioning of the guide sheath in the distal CCA, predilation balloon angioplasty was performed under distal embolic protection followed by stent placement across the stenosis. Poststent right carotid injection showed increased perfusion of the distal right ICA (Fig 3C). There was no neurologic decline postprocedurally. The patient was discharged home on day 3 with a baseline neurologic examination. At 1-month and 1-year follow-up, there were no neurologic changes, and 1-year sonography revealed a left ICA PSV of 78 $\mathrm{cm} / \mathrm{s}$ and a left ICA/CCA PSV ratio of 0.80 .

\section{DISCUSSION}

Before the NASCET and ECST subgroup studies, carotid near-occlusion was thought to carry a high short-term stroke risk that required emergent revascularization. ${ }^{15}$ Re-analysis of the data showed that the risk is lower than originally thought. In pooled data for patients with near-occlusion from NASCET and ECST, the 3-year intention-to-treat risk of ipsilateral stroke was $15.1 \%$ for medically treated and $10.9 \%$ for surgically treated patients. In contrast, the pooled data for severe stenosis (70\%-99\%) without near-occlusion from NASCET and ECST described a 3-year intention-to-treat risk of ipsilateral stroke of $26.0 \%$ for medically treated and $8.2 \%$ for surgically treated patients. ${ }^{4}$ Although the benefit of CEA in near-occlusion did not reach statistical significance, there was a trend toward benefit with CEA compared with medical management. The risk of revascularization in near-occlusion was also thought initially to be high, but NASCET and ECST showed complication rates lower than in the severe steno- 


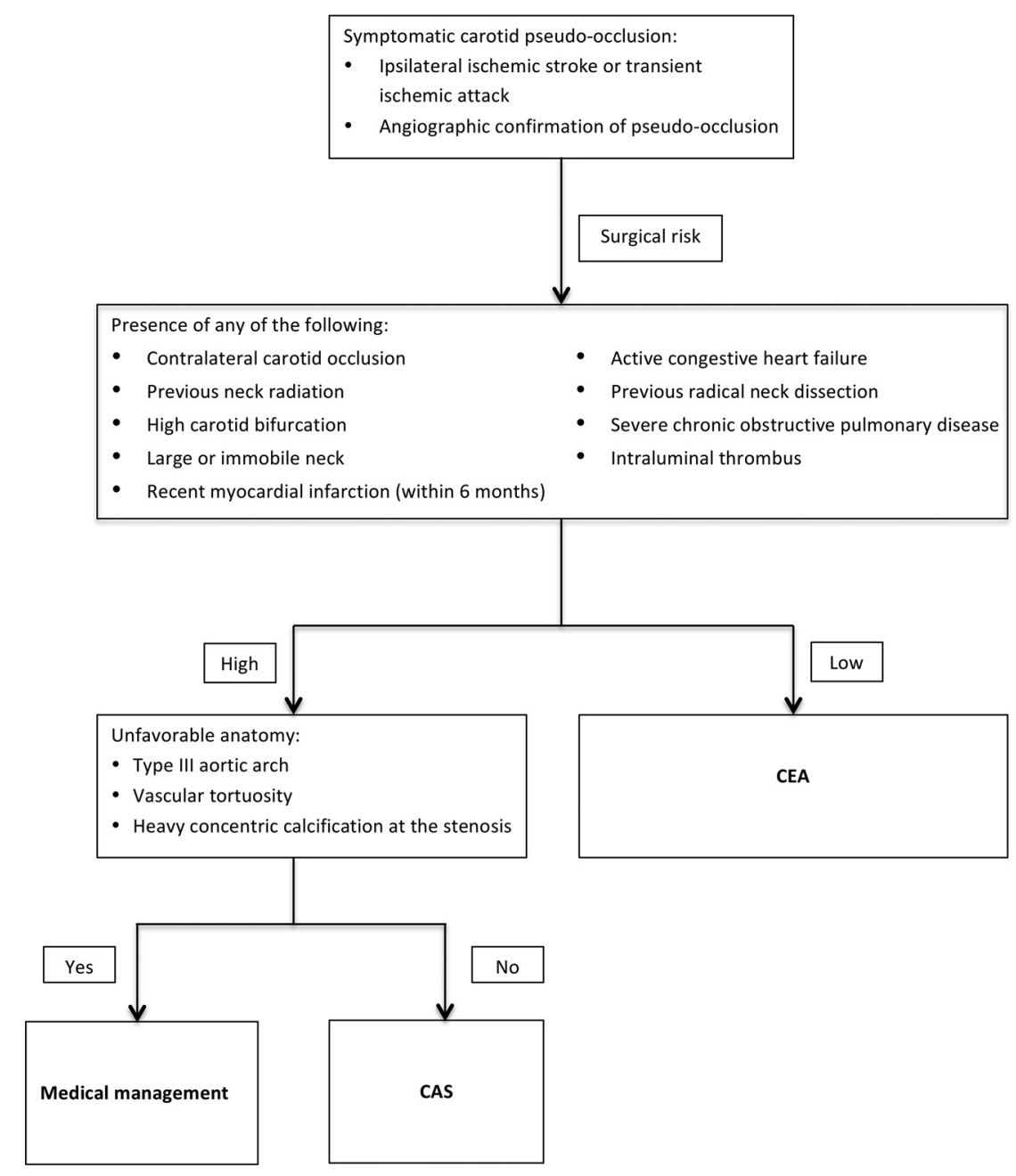

FIG 4. Algorithm for the management of symptomatic near-occlusion of the internal carotid artery.

noid hemorrhage with no neurologic deficit or any sequelae. At 1-year follow-up, no patients in either group experienced any strokes or myocardial infarctions. One patient in the CAS group died shortly after 1-year follow-up of a non-neurologic cause from acute heart failure. One patient who was not included in study analysis due to inadequate follow-up had femoral artery pseudoaneurysm and symptomatic reperfusion intracerebral hemorrhage.

The use of carotid stent placement has been accepted as an alternative option to CEA after approval by the Food and Drug Administration of CAS based on the Stenting and Angioplasty with Protection in Patients at High Risk for Endarterectomy (SAPPHIRE) trial. ${ }^{16}$ The Carotid Revascularization Endarterectomy versus Stenting Trial (CREST) also demonstrated no difference in composite outcomes (stroke, myocardial infarction, or death) between CEA and CAS. ${ }^{13}$ However, these studies did not include patients with near-occlusion. Near-occlusion would appear to be technically prohibitive of endovascular treatment, but in our series, only 1 patient selected for CAS had crossover to the CEA group. Due to tortuosity of the aortic arch as well as the degree of stenosis, the microwire and the microcatheter could not be crossed through the stenosis safely. The patient subsequently underwent technically successful CEA with patch angioplasty.
Until now, there has been scarce data on comparison between CEA and CAS in the literature for treatment of nearocclusion, and choosing 1 method for revascularization can be difficult. Our study shows similar outcomes and success rate as well as imaging outcomes in 1-year follow-up. As with any carotid revascularization, medical comorbidities and anatomic risk factors must be considered when choosing between CAS or CEA. We performed CAS on patients whom we determined had high risk factors for CEA. We determined that certain anatomic features of near-occlusion, including heavy concentric calcification ( $\geq 3 \mathrm{~mm}$ in width by at least 2 orthogonal views) or vascular tortuosity ( $\geq 2$ bend point that exceeded $90^{\circ}$ within $5 \mathrm{~cm}$ of the lesion), prohibited safe CAS placement. ${ }^{17}$ In these patients, we opted for CEA. High-risk anatomic factors for CEA include a high carotid bifurcation, intraluminal thrombus, ${ }^{18}$ a large or immobile neck, previous neck irradiation, prior neck operation, and contralateral carotid occlusion.

We used our algorithm (Fig 4) for selection of patients to CEA, CAS, or medical management. This algorithm does not depart greatly from our typical management of symptomatic carotid stenosis. The main difference in our management of near-occlusion is a higher threshold to perform stent placement. A full collapse of the ICA distal to the near-occlusion will not allow a stent to expand fully, and this has deterred but not prohibited us from performing this procedure more frequently in this setting. While concentric calcification is an accepted contraindication to carotid stent placement, we have also been averse to placing carotid stents in near-occlusions with severe eccentric calcification. We have been concerned that the stent may not expand adequately against heavy calcification in an already constrained vessel.

Our clinical practice is to follow up all patients with carotid sonography at 1 month and 1 year. Near-occlusion typically results in decreased flow distal to the stenosis, resulting in a hypoplastic vessel. Vessel maturation was assessed at either 1-month or 1-year imaging in all patients. In our study, vessel maturation was noted in 21 (84\%) patients in the CEA group and 11 (79\%) patients in CAS group. However, our overall restenosis rate at 1 year $(\sim 20 \%)$ appears notably higher than that seen following revascularization of carotid stenosis without near-occlusion $(4 \%-$ $5 \%)$ at 1 year in CREST. ${ }^{19}$ Patients who had restenosis or occlusion did not have any recurrence of neurologic deficits; 4 of 6 patients were able to undergo additional angioplasty without complications. However, 2 patients did not undergo angioplasty 
because they presented with delayed occlusion of the carotid artery after CEA with patch angioplasty, which is a higher rate of occlusion than that seen in CEA for severe stenosis without nearocclusion. Neither patient was symptomatic, and the acuity of the occlusion could not be assessed accurately due to occlusion being discovered during normal follow-up periods. While this outcome is consistent with assertions from NASCET authors ${ }^{4}$ that the stroke risk from near-occlusion is not a flow-related phenomenon but mostly an embolic phenomenon, it also suggests that revascularization after near-occlusion may have a higher risk of restenosis and/or occlusion, which has not been previously described.

Our data have several limitations, including the nonrandomized, retrospective nature of patient selection and follow-up. Patients were not randomly assigned to CEA versus CAS; CEA was the preferred option unless high-risk features favored CAS. We studied only patients with near-occlusion who underwent revascularization, and we did not include patients who underwent medical treatment alone. In patients at high risk of either CEA or CAS based on anatomic factors or comorbidities (eg, active congestive heart failure and concentrically calcified carotid near-occlusion), medical treatment may be the most reasonable option because the benefit of revascularization appears to be modest. Current medical management options have advanced since NASCET and ECST; this change may further improve outcomes of medically treated patients with near-occlusion. In addition, the sample size of our study is small, and to detect a difference between these 2 groups for periprocedural stroke rates for the treatment of symptomatic near-occlusion, we would need a sample size of $11,972 .{ }^{9,11}$

\section{CONCLUSIONS}

Both CEA and CAS seem to be safe and effective treatments for patients with symptomatic carotid near-occlusion with low complication rates periprocedurally and at 1 year. CAS is a good alternative if the patient has a high risk for CEA.

Disclosures: Ramachandra P. Tummala_UNRELATED: Grants/Grants Pending: MicroVention, Comments: unrestricted fellowship education grant, not used for the submitted work. * Money paid to the institution.

\section{REFERENCES}

1. Lippman HH, Sundt TM Jr, Holman CB. The poststenotic carotid slim sign: spurious internal carotid hypolasia. Mayo Clin Proc 1970; 45:762-67 Medline

2. Ferguson GG, Eliasziw M, Barr HW, et al. The North American Symptomatic Carotid Endarterectomy Trial: surgical results in 1415 patients. Stroke 1999;30:1751-58 CrossRef Medline

3. Randomised trial of endarterectomy for recently symptomatic ca- rotid stenosis: final results of the MRC European Carotid Surgery Trial (ECST). Lancet 1998;351:1379-87 CrossRef Medline

4. Fox AJ, Eliasziw M, Rothwell PM, et al. Identification, prognosis, and management of patients with carotid artery near occlusion. AJNR Am J Neuroradiol 2005;26:2086-94 Medline

5. Johansson E, Öhman K, Wester P. Symptomatic carotid near-occlusion with full collapse might cause a very high risk of stroke. J Intern Med 2015;277:615-23 CrossRef Medline

6. Johansson E, Fox AJ. Carotid near-occlusion: a comprehensive review, Part 1: definition, terminology, and diagnosis. AJNR Am J Neuroradiol 2016;37:2-10 CrossRef Medline

7. Morgenstern LB, Fox AJ, Sharpe BL, et al. The risks and benefits of carotid endarterectomy in patients with near occlusion of the carotid artery. North American Symptomatic Carotid Endarterectomy Trial (NASCET) Group. Neurology 1997;48:911-15 CrossRef Medline

8. Terada T, Tsuura M, Matsumoto H, et al. Endovascular treatment for pseudo-occlusion of the internal carotid artery. Neurosurgery 2006;59:301-09; discussion 301-09 CrossRef Medline

9. González A, Gil-Peralta A, Mayol A, et al. Internal carotid artery stenting in patients with near occlusion: 30-day and long-term outcome. AJNR Am J Neuroradiol 2011;32:252-58 CrossRef Medline

10. Koutsoumpelis A, Kouvelos G, Peroulis M, et al. Surgical and endovascular intervention on internal carotid artery near occlusion. Int Angiol 2015;34:172-81 Medline

11. Rothwell PM, Eliasziw M, Gutnikov SA, et al; Carotid Endarterectomy Trialists' Collaboration. Analysis of pooled data from the randomised controlled trials of endarterectomy for symptomatic carotid stenosis. Lancet 2003;361:107-16 CrossRef Medline

12. Bonati LH, Dobson J, Featherstone RL, et al; International Carotid Stenting Study Investigators. Long-term outcomes after stenting versus endarterectomy for treatment of symptomatic carotid stenosis: the International Carotid Stenting Study (ICSS) randomised trial. Lancet 2015;385:529-38 CrossRef Medline

13. Brott TG, Hobson RW 2nd, Howard G, et al; CREST Investigators. Stenting versus endarterectomy for treatment of carotid-artery stenosis. N Engl J Med 2010;363:11-23 CrossRef Medline

14. Setacci C, Chisci E, Setacci F, et al. Grading carotid intrastent restenosis: a 6-year follow-up study. Stroke 2008;39:1189-96 CrossRef Medline

15. Ringelstein EB, Berg-Dammer E, Zeumer H. The so-called atheromatous pseudoocclusion of the internal carotid artery: a diagnostic and therapeutical challenge. Neuroradiology 1983;25:147-55 CrossRef Medline

16. Yadav JS, Wholey MH, Kuntz RE, et al; Stenting and Angioplasty with Protection in Patients at High Risk for Endarterectomy Investigators. Protected carotid-artery stenting versus endarterectomy in highrisk patients. N Engl J Med 2004;351:1493-501 CrossRef Medline

17. Roubin GS, Iyer S, Halkin A, et al. Realizing the potential of carotid artery stenting: proposed paradigms for patient selection and procedural technique. Circulation 2006;113:2021-30 CrossRef Medline

18. Jahromi BS, Tummala RP, Yamamoto J, et al. Early carotid stenting for symptomatic stenosis and intraluminal thrombus presenting with stroke. Neurology 2008;71:1831-13 CrossRef Medline

19. Brott TG, Howard G, Roubin GS, et al; CREST Investigators. Longterm results of stenting versus endarterectomy for carotid-artery stenosis. N Engl J Med 2016;374:1021-31 CrossRef Medline 